\title{
The action of the C-terminal octapeptide of cholecystokinin and related peptides on pancreatic exocrine secretion
}

\author{
SUMIO NAKAJIMA ${ }^{1}$ \\ From the 2nd Department of Internal Medicine, Nagoya University School of Medicine, Nagoya, Japan
}

SUMMARY The effect of the C-terminal octapeptide of cholecystokinin-pancreozymin (CCK-PZ), caerulein, and the C-terminal tetrapeptide of gastrin on pancreatic secretion of fluid, electrolyte, amylase, and protein was studied in anaesthetized dogs prepared with pancreatic fistulae. Against background stimulation of fluid secretion with submaximal doses of secretin, all the polypeptides produced a qualitatively similar pancreatic response, causing a highly significant increase in amylase, protein, calcium, and zinc concentrations. Magnesium concentration was significantly increased only when the concentration preceding the administration of the peptide was below $100 \mu$-equiv/l. OctaCCK-PZ was 13-35 times and 20-56 times more potent than tetragastrin on weight and molar bases, respectively, as a stimulant of amylase secretion. The threshold doses were largest for amylase, lower for calcium, and lowest for zinc. A significant linear correlation was observed between amylase and calcium concentration, zinc and protein concentration, and magnesium and calcium concentration. The peptides produced some increase in secretin-induced volume flow, whereas bicarbonate, chloride, sodium, and potassium concentrations remained unchanged. The direct relation between bicarbonate concentration and flow rate was limited to rates below $1.5 \mathrm{ml} / 5$ minutes. At higher rates bicarbonate and chloride concentration reached a high and low plateau, respectively, although the first five-min sample of pancreatic juice after secretin stimulation exhibited a relatively low bicarbonate and high chloride concentration compared with its voluminous flow. Chloride concentration varied inversely with bicarbonate concentration, the sum of the two anions being constant.

The intestinal hormone cholecystokinin/pancreozymin (CCK-PZ), for which a partial structure has been proposed, is a single-chain polypeptide with 33 amino acid residues (Mutt and Jorpes, 1968). The C-terminal pentapeptide of CCK-PZ is structurally identical with that of the gastric hormone gastrin, and also of the decapeptide caerulein, isolated from the skin of Hyla caerulea (Anastasi, Erspamer, and Endean, 1968). Recently Pluščc, Sheehan, Sabo, Williams, Kocy, and Ondetti (1970) have synthesized the C-terminal octapeptide of CCK-PZ (octa CCK-PZ) which possesses the biological activities of the full hormonal molecule.

It has been demonstrated that octa CCK-PZ is more potent, on weight and molar bases, than the

\footnotetext{
${ }^{1}$ Address for correspondence: Sumio Nakajima, MD, 2nd Department of Internal Medicine, Nagoya University School of Medicine, Tsuruma-Cho 65, Showa-Ku, Nagoya, Japan

Received for publication 3 May 1973.
}

entire hormone in contracting the gallbladder and bowel as well as in promoting secretion of pancreatic protein (Rubin, Engel, Drungis, Dzelzkalns, Grigas, Waugh, and Yiacas, 1969; Rubin, 1972). In addition it has been shown to inhibit acid secretion in one type of isolated fundic gastric mucosa and to stimulate it in another (Nakajima, Hirschowitz, Shoemaker, and Sachs, 1971).

The object of the present investigation was to determine the effects of octa CCK-PZ, caerulein, and the C-terminal tetrapeptide of gastrin (tetragastrin) on pancreatic secretion of enzyme and electrolytes. Special emphasis was laid on the interrelationships in the composition of pancreatic juice.

\section{Materials and Methods}

Adult mongrel dogs of either sex, weighing between 10 and $20 \mathrm{~kg}$, were fasted for approximately 20 hours. Animals were anaesthetized with sodium 
pentobarbital $(25-30 \mathrm{mg} / \mathrm{kg})$ injected intravenously. A tube was placed in the trachea and connected to an artificial respirator throughout the experiment. The abdomen was opened through a midline incision. A simple gastric fistula was constructed and a rubber ligature was placed around the pylorus to prevent the entry of acid into the duodenum. A total pancreatic fistula was prepared as described previously (Nakajima and Magee, 1970). A continuous intravenous infusion of $0 \cdot 15 \mathrm{M} \mathrm{NaCl}$ was delivered throughout each experiment at a rate of $50 \mathrm{ml} / \mathrm{hr}$ by a motor-driven syringe. Secretin was then added to the infusion to give the desired dosage. Two types of secretin were used: Squibb synthetic secretin in clinical units and Boots secretin in Crick, Harper, and Raper units. Pancreatic juice was collected continuously into a graduated centrifuge tube through a 30-cm polyethylene cannula (PE 100) at, unless otherwise stated, 15-min intervals.

The activity of amylase was determined by the method of Caraway (1959) wherein the unhydrolyzed starch was measured spectrophotometrically following the reaction with iodine. Bicarbonate was estimated either by the gasometric method of Natelson (1951) using an EKDS microgasometer or by a modification of the titrimetric method of Segal (1955). Chloride was determined in a Hiranuma chloride counter (type CL-1) developed for use with the automatic coulometric-amperometric titrator described by Cotlove, Trantham, and Bowman (1958). Sodium, potassium, calcium, magnesium, and zinc were determined in a Hitachi-Perkin Elmer model 303 atomic absorption spectrophotometer (Slavin, 1968). To determine calcium and magnesium, protein was precipitated with $9 \%$ trichloroacetic acid and the specimens were diluted in a $1 \%$ lanthanum chloride solution. The protein content of pancreatic juice was determined by measuring light absorption at $540 \mathrm{~m} \mu$ in a Hitachi spectrophotometer following biuret reaction and comparing the results with a standard solution of bovine serum albumin.

The C-terminal octapeptide of CCK-PZ (SQ 19844) was a gift from Dr M. A. Ondetti, Squibb Institute for Medical Research, New Brunswick, New Jersey. Caerulein (FI 6934) was kindly supplied by the Farmitalia Laboratories for Basic Research, Milan, Italy. The C-terminal tetrapeptide amide of gastrin in the form of carbobenzoxy-Try-Met-AspPhe- $\mathrm{NH}_{2}$ (tetragastrin) was given by Nissui Seiyaku Co, Tokyo, Japan.

Statistical significance was evaluated either by application of the $t$ test for non-paired samples or by calculation of correlation coefficients. Regression lines were calculated by the method of least squares (Snedecor and Cochran, 1967). The null hypothesis was rejected at the $5 \%$ level.

\section{Results}

EFFECT OF VARYING DOSES OF OCTA CCK-PZ INJECTION ON VOLUME AND AMYLASE AND CALCIUM CONCENTRATIONS OF PANCREATIC JUICE

Figure 1 illustrates the effect of rapid intravenous injections of octa CCK-PZ on pancreatic secretion induced by secretin. In all experiments, no amount of spontaneously flowing juice could be collected immediately before secretin stimulation. Continuous intravenous infusion of secretin alone in a dose of 4.0 units $/ \mathrm{kg}$-hr for $225 \mathrm{~min}$ resulted in an average 15 -min volume of $9.2 \mathrm{ml}$. Volume increased with time with only two exceptions and the largest mean 15 -min volume was $10.8 \mathrm{ml}$ during the last 15 -min collection period. Amylase and calcium concentrations were high during the first 15 -min period, but fell off quickly within the next 15 min reaching a plateau that persisted throughout the remainder of the experiment. The mean pre-injection levels in the test and control experiments with secretin did not differ significantly $(P<0.05)$. The rapid intravenous injection of 2 to $128 \mu \mathrm{g}(0.15$ to $10.7 \mu \mathrm{g} / \mathrm{kg})$ of octa CCK-PZ increased the volume of the flow during the first 15 -min period by 16.6 to $42.0 \%$ from the control. When octa CCK-PZ volume responses and secretin controls were compared individually, the difference was not significant $(P>0.05)$. When, however, the whole response after octa CCK-PZ was

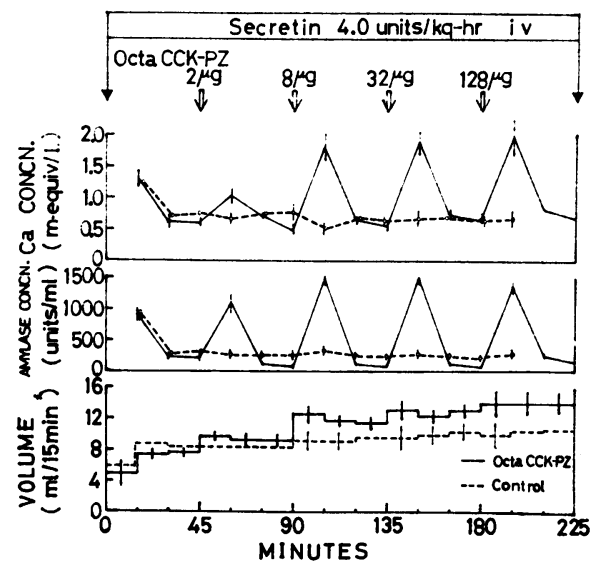

Fig 1 Effect of single rapid intravenous injection of octa $C C K-P Z$ on volume flow, amylase, and calcium concentrations in 15-min samples of pancreatic juice secreted in response to continuous intravenous infusion of Boots secretin. In control experiments, secretin alone was given throughout the experiment. Means $\pm S E$ for five experiments in five dogs weighing $12-13 \mathrm{~kg}$. 


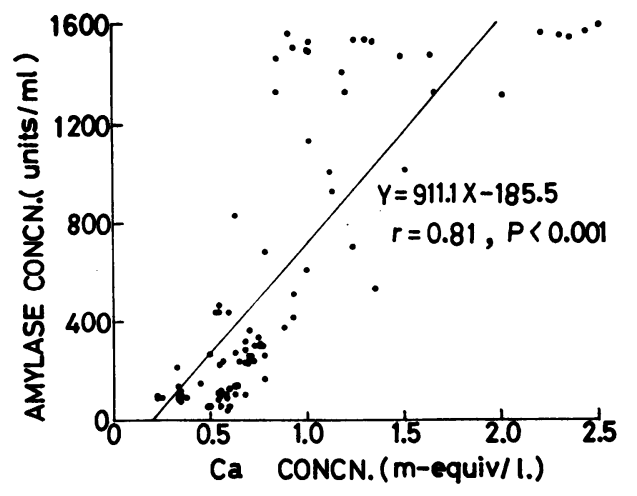

Fig 2 Relationship between amylase and calcium concentration in 15-min samples of pancreatic juice secreted in response to continuous intravenous infusion of secretin alone and in combination with octa CCK-PZ. Calculated regression line is shown.

compared with the whole secretin control over the same 90-225 min period, it was evident that octa CCK-PZ significantly augmented volume flow $(\mathrm{P}<$ 0.05 ). The injection of 0.15 to $10.7 \mu \mathrm{g} / \mathrm{kg}$ octa CCK-PZ significantly increased the amylase and calcium concentrations of pancreatic juice. The threshold dose causing a significant increase in amylase concentration varied from 0.045 to 0.090 $\mu \mathrm{g} / \mathrm{kg}$. As shown in fig 2 , there was a significant linear correlation between amylase and calcium concentrations of pancreatic juice.

EFFECT OF VARYING DOSES OF OCTA CCK-PZ INJECTION ON BICARBONATE, CHLORIDE, SODIUM, AND POTASSIUM CONCENTRATIONS OF PANCREATIC JUICE

Figure 3 illustrates the effect of rapid intravenous injections of octa CCK-PZ on pancreatic electrolyte secretion. The bicarbonate, chloride, sodium, and potassium responses to octa CCK-PZ were not significantly different from those to secretin alone $(P>0.05)$. The peak bicarbonate concentration was obtained during the second 15 -min period. Thereafter, despite persistently high volumes of secretion, the bicarbonate concentration was found to decrease gradually throughout. The chloride concentration varied inversely with bicarbonate concentration so that the sum of the two anions remained constant. Sodium and potassium concentrations remained fairly constant throughout, and the sum of the three cations, including calcium, was below that of the anions with three exceptions.

No significant correlation between bicarbonate and volume flow was obtained (fig $4, r=0.11$, P > 0.1).

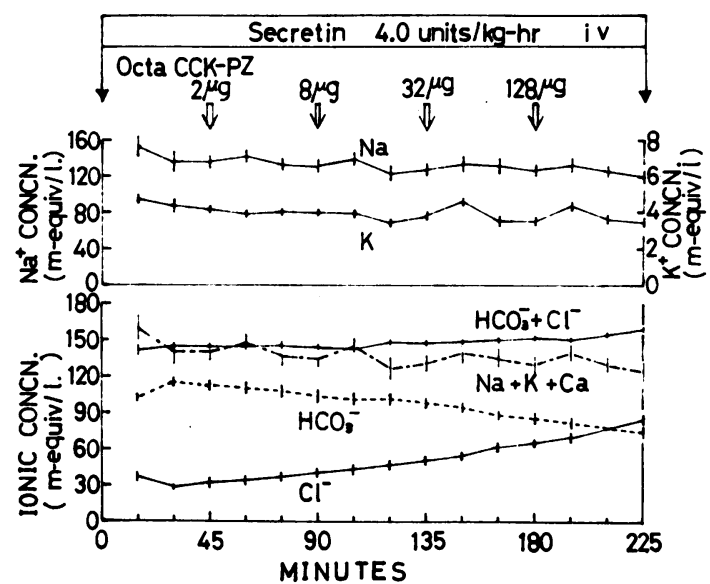

Fig 3 Effect of single rapid intravenous injection of octa CCK-PZ on bicarbonate, chloride, sodium, and potassium concentrations in 15-min samples of pancreatic juice secreted in response to continuous intravenous infusion of Boots secretin. Means $\pm S E$ for five experiments in five dogs weighing $12-13 \mathrm{~kg}$.

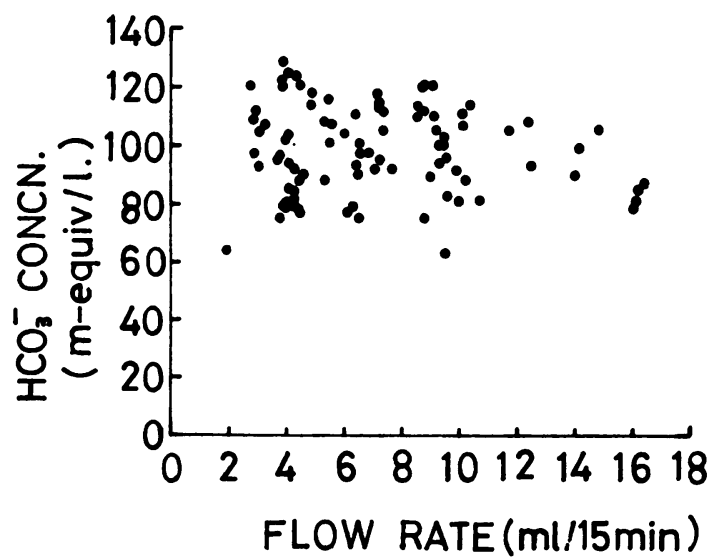

Fig 4 Relationship between bicarbonate concentration and volume flow in 15-min samples of pancreatic juice secreted in response to continuous intravenous infusion of secretin alone and in combination with octa CCK-PZ.

As shown in fig 5, there was an inverse linear correlation between bicarbonate and chloride concentrations. The slope of the regression line was not significantly different from $-1(P>0.05)$.

EFFECT OF CONTINUOUS INTRAVENOUS ADMINISTRATION OF OCTA CCK-PZ ON PANCREATIC SECRETION INDUCED BY SECRETIN

The effect of a continuous intravenous infusion for two hours of $1.4 \mu \mathrm{g} / \mathrm{kg}-\mathrm{hr}$ octa CCK-PZ on volume, 


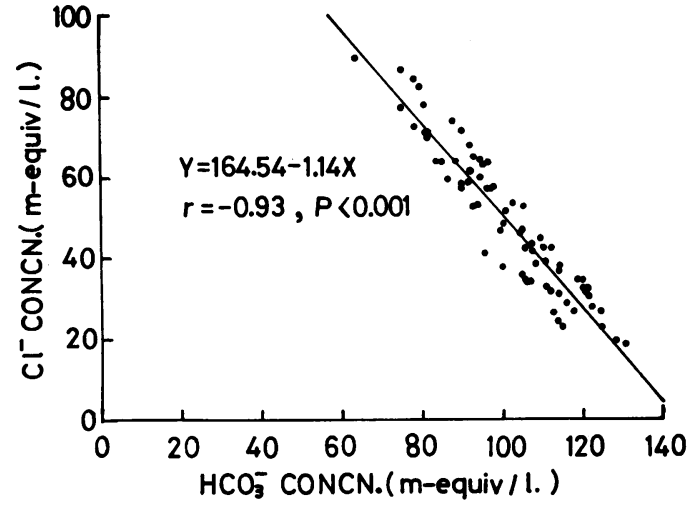

Fig 5 Relationship between chloride and bicarbonate concentration in 15-min samples of pancreatic juice secreted in response to continuous intravenous infusion of secretin alone and in combination with octa CCK-PZ. Calculated regression line is shown.

electrolytes, amylase, and protein secretion in response to secretin was tested in two experiments. One experiment is depicted in figure 6. Whereas bicarbonate, chloride, sodium, and potassium concentrations were virtually unaltered, calcium, zinc, amylase, and protein concentrations showed a prompt and sharp increase during the first 15-min period after starting the infusion. Calcium and zinc concentration reached a peak during the third 15-min period after the start of the infusion and then declined gradually. The increases in amylase, protein, and calcium concentration, which were

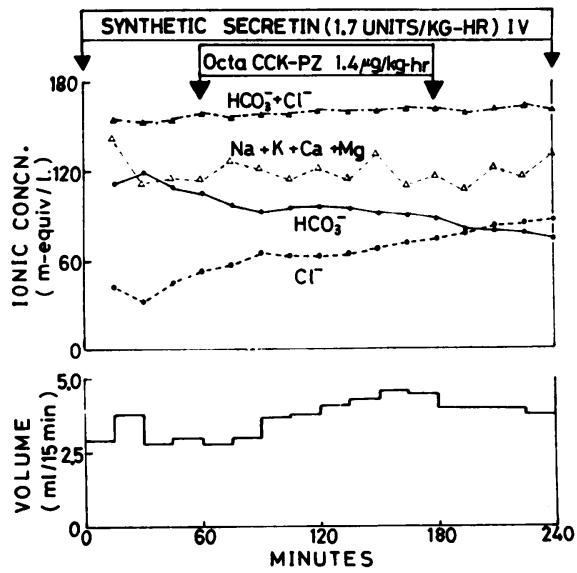

Fig 6 One experiment illustrating the effect of continuous intravenous infusion of octa CCK-PZ in a dose of $1.4 \mu \mathrm{g} / \mathrm{kg}$ - $\mathrm{hr}$ on volume, bicarbonate and chloride concentrations, and the sum of anions and that of cations in 15-min samples of pancreatic juice secreted in response to secretin. relatively short lived following single injections (fig 1), persisted throughout the two-hr period of continuous infusion of octa CCK-PZ although there was a gradual reduction in amylase, protein, and calcium concentrations during the second hour. The amylase and protein concentrations increased to more than $240 \%$ above the preinfusion level within $15 \mathrm{~min}$ and these values were maintained for one $\mathrm{hr}$ and fell to only $199 \%$ of the preinfusion levels by the end of the second hour. Concentrations of calcium and zinc, which also rapidly increased to peak values, $152 \%$ for calcium and $19900 \%$ for zinc above preinfusion levels, began to decline after $45 \mathrm{~min}$, and were $58 \%$ for calcium and $9900 \%$ for zinc above the preinfusion level at the end of two hours. The magnesium concentration was largest, ranging from 190 to $330 \mu$-equiv/l, in the first sample obtained after starting secretin infusion in all series of experiments. In the two experiments with octa CCK-PZ infusion the preinfusion levels of magnesium were 160 and $66 \mu$-equiv/l, respectively, and were unchanged in the former and increased to 165 $\mu$-equiv/l in the latter.

\section{EFFECT OF CONTINUOUS INTRAVENOUS ADMINISTRATION OF CAERULEIN ON PANCREATIC SECRETION INDUCED BY SECRETIN}

Figures 7 and 8 illustrate the effect of a continuous two-hr intravenous infusion of $1.4 \mu \mathrm{g} / \mathrm{kg}-\mathrm{hr}$ caerulein on volume, electrolytes, and amylase secretion in response to secretin. While the bicarbonate-chloride reciprocal relationship and sodium and potassium concentrations remained unaltered, amylase, calcium, and magnesium concentrations were markedly increased, attaining the peak during the first 15 -min period after starting the infusion. The magnesium concentration immediately preceding the infusion of caerulein was $70 \mu$-equiv/1. Caerulein caused a $143 \%$ increase in magnesium concentration to $170 \mu$ equiv $/ 1$ in the first $15 \mathrm{~min}$ and thereafter the concentration, although fluctuating, gradually fell to 130 $\mu$-equiv/ 1 by the end of the second hour of infusion. The progressive reduction in calcium concentration was more conspicuous than that in amylase and magnesium concentrations. One additional experiment gave similar results.

Caerulein produced a marked increase in zinc and protein concentrations of pancreatic juice. Figure 9 shows the relationship between zinc and protein concentrations of pancreatic juice collected during the intravenous infusion of secretin alone and in combination with caerulein. A significant linear correlation was obtained between the two components. 


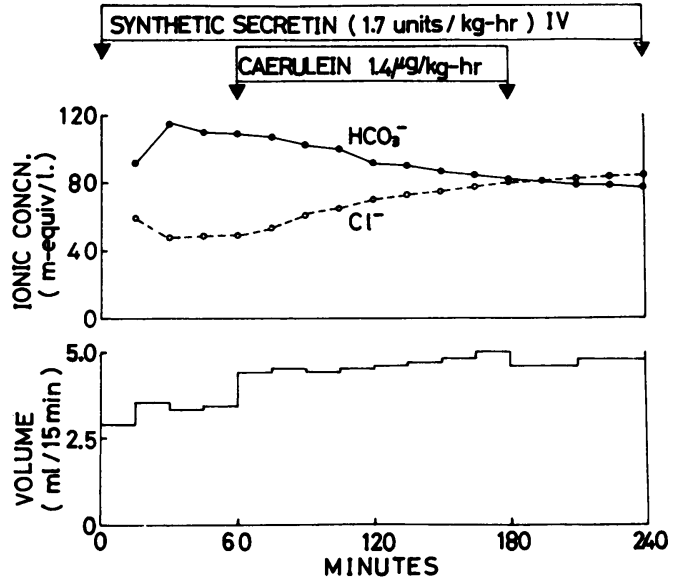

Fig 7 An example of the effect of a continuous intravenous infusion of caerulein in a dose of $1.4 \mu \mathrm{g} / \mathrm{kg}-\mathrm{hr}$ on volume and bicarbonate and chloride concentrations in 15-min samples of pancreatic juice secreted in response to secretin.

\section{EFFECT OF CONTINUOUS INTRAVENOUS ADMINISTRATION OF TETRAGASTRIN ON PANCREATIC SECRETION INDUCED BY SECRETIN}

The effect of a continuous intravenous infusion of three doses of tetragastrin on electrolytes, amylase, and protein concentrations was tested in three experiments, one of which is illustrated in figures 10 and 11. Tetragastrin in stepwise doses of $7 \cdot 0,14 \cdot 0$, and $28.0 \mu \mathrm{g} / \mathrm{kg}-\mathrm{hr}$ produced an increase more than

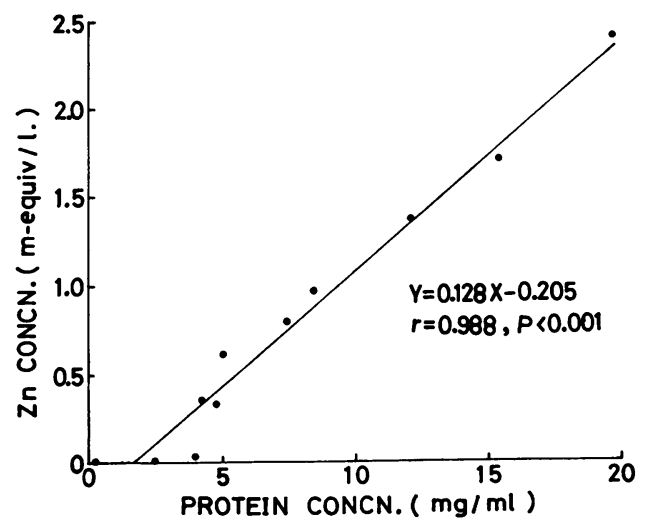

Fig 9 Relationship between zinc and protein concentration in 15-min samples of pancreatic juice secreted in response to continuous intravenous infusion of secretin alone and in combination with caerulein. Calculated regression line is shown.

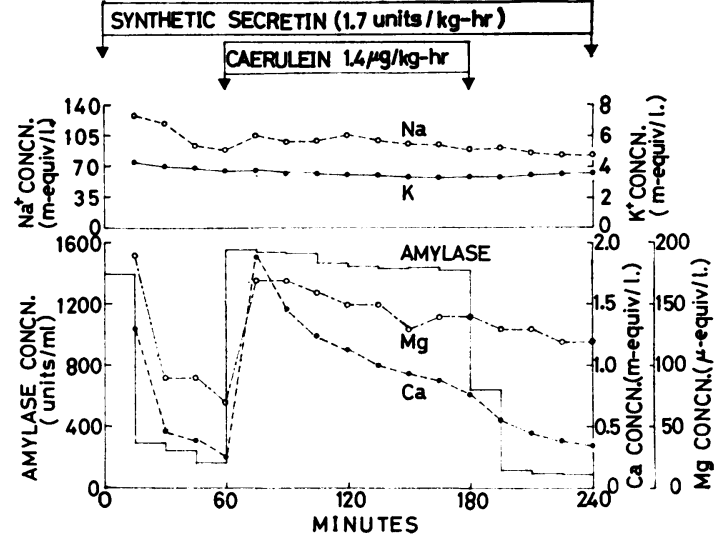

Fig 8 Effect of a continuous intravenous infusion of caerulein in a dose of $1.4 \mu \mathrm{g} / \mathrm{kg}-\mathrm{hr}$ on sodium, potassium, calcium, magnesium, and amylase concentrations in 15-min samples of pancreatic juice secreted in response to secretin. The same experiment as shown in figure 7.

$375 \%$ from the preinfusion level in amylase, protein. calcium, and zinc concentrations. Sodium and potassium concentrations remained approximately constant throughout the experiment. The preinfusion level of magnesium was $123 \mu$-equiv/l and the concentration fluctuated between 107 and 208 $\mu$-equiv/l during the succeeding three-hr infusion period. While tetragastrin in a dose of $1.4 \mu \mathrm{g} / \mathrm{kg}-\mathrm{hr}$ failed to increase amylase concentration, it caused a significant increase in zinc and calcium concentrations during the infusion period. The threshold dose of tetragastrin, capable of producing a significant increase in amylase concentration, ranged from 4.0 to $5.5 \mu \mathrm{g} / \mathrm{kg}-\mathrm{hr}$ by a continuous infusion and from 1.2 to $1.6 \mu \mathrm{g} / \mathrm{kg}$ by a single rapid injection.

\section{EFFECT OF SINGLE RAPID INTRAVENOUS} INJECTION OF TETRAGASTRIN ON PANCREATIC SECRETION INDUCED BY SECRETIN

The table summarizes the pancreatic response to varying injected doses of tetragastrin. A single rapid intravenous injection of tetragastrin in a dose of 0.2 $\mu \mathrm{g} / \mathrm{kg}$ which failed to cause any significant increase in amylase content produced $502 \%$ increase in zinc concentration and $8 \%$ increase in calcium concentration from the preinfusion level during the first 15-min period. The threshold dose of tetragastrin was largest for amylase, lower for calcium, and lowest for zinc. On the basis of the stimulant activity of amylase, octa CCK-PZ was 13-35 times and 20-56 times more potent than tetragastrin on weight and molar bases, respectively. 


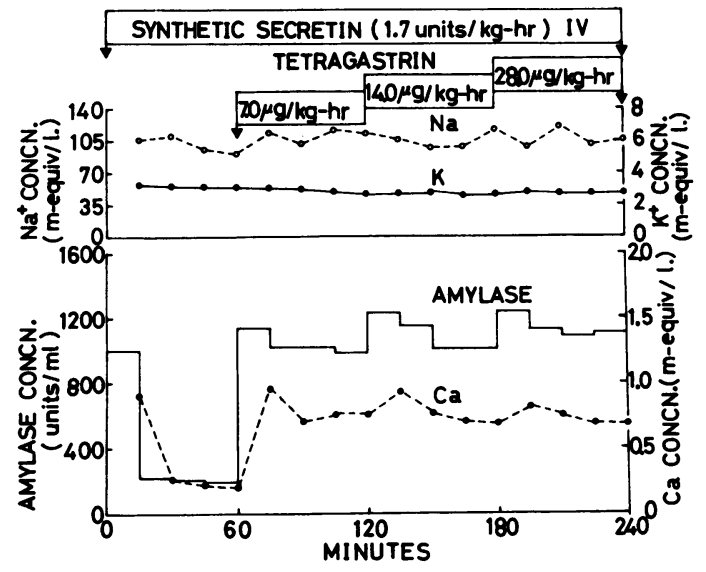

Fig 10 An example of the effect of a continuous intravenous infusion of tetragastrin in stepwise increasing doses on sodium, potassium, calcium, and amylase concentrations in 15-min samples of pancreatic juice secreted in response to secretin.

\section{RELATIONSHIP BETWEEN MAGNESIUM AND CALCIUM CONCENTRATIONS OF PANCREATIC JUICE}

Figure 12 shows the relation of magnesium concentration to calcium concentration of pancreatic juice collected during the intravenous infusion of secretin alone and in combination with the polypeptide studied. There was a significant linear correlation between magnesium and calcium concentrations.

\section{EFFECT OF A SINGLE RAPID INTRAVENOUS} INJECTION OF SECRETIN IN A NEAR MAXIMAL DOSE ON PANCREATIC AMYLASE AND ELECTROLYTE SECRETION

To provide further information on the relationship between volume flow and electrolyte concentration of pancreatic juice, the pancreatic response to a single

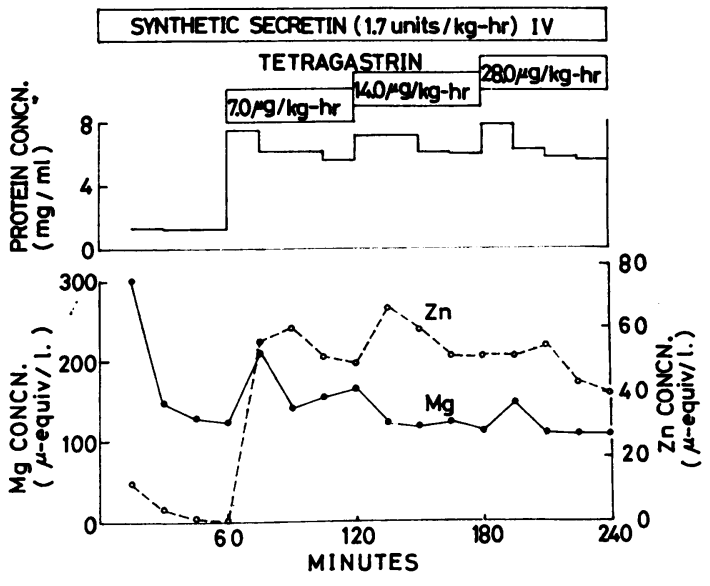

Fig 11 Effect of a continuous intravenous infusion of tetragastrin in stepwise increasing doses on zinc, magnesium, and protein concentrations in 15-min samples of pancreatic juice in response to secretin. The same experiment as shown in figure 10.

rapid intravenous injection of synthetic secretin in a large dose was investigated in consecutive five-min samples of pancreatic juice. It can be seen in fig 13 that secretin in a dose of $3 \cdot 2$ clinical units $/ \mathrm{kg}$ produced a rapid increase in volume from zero level, reaching the highest level, $6.6 \mathrm{ml} / 5 \mathrm{~min}$, during the second five-min period. Thereafter volume of flow diminished progressively and ceased at the time of $50 \mathrm{~min}$ after the injection of secretin. The first five-min sample had a high amylase content as a washout phenomenon. As the bicarbonate concentration rose to a high plateau, the amylase content fell to a low level. Subsequently, amylase concentration began to increase during the seventh five-min period as the volume of flow decreased rapidly.

Bicarbonate and chloride concentrations remained approximately constant at the flow rates above 1.4 $\mathrm{ml} /$ five min, although the first five-min sample showed a relatively low bicarbonate and high

\begin{tabular}{|c|c|c|c|c|c|c|}
\hline & \multirow{2}{*}{$\begin{array}{l}\text { Pretreatment } \\
\text { Level }\end{array}$} & \multicolumn{5}{|c|}{ Tetragastrin $(\mu \mathrm{g} / \mathrm{kg})$} \\
\hline & & 0.2 & 0.4 & 0.8 & 1.6 & $3 \cdot 2$ \\
\hline $\begin{array}{l}\text { Volume (ml/15 min) } \\
\mathrm{Zn} \text { concentration (m-equiv/1) } \\
\text { Ca concentration (m-equiv/l) } \\
\text { Amylase (units/ml) }\end{array}$ & $\begin{array}{l}9.9 \pm 2.0 \\
0.018 \pm 0.004 \\
0.89 \pm 0.32 \\
300 \pm 85\end{array}$ & $\begin{array}{l}10 \cdot 0 \pm 2 \cdot 5 \\
0 \cdot 110 \pm 0 \cdot 021 \\
0.97 \pm 0.40 \\
297 \pm 95\end{array}$ & $\begin{array}{l}10 \cdot 1 \pm 2 \cdot 1 \\
0 \cdot 162 \pm 0 \cdot 035 \\
1 \cdot 06 \pm 0 \cdot 45 \\
297 \pm 96\end{array}$ & $\begin{array}{l}10 \cdot 1 \pm 1 \cdot 8 \\
0 \cdot 174 \pm 0 \cdot 032 \\
1 \cdot 36 \pm 0 \cdot 51 \\
320 \pm 96\end{array}$ & $\begin{array}{l}9 \cdot 1 \pm 2 \cdot 0 \\
0 \cdot 254 \pm 0.053 \\
1 \cdot 41 \pm 0 \cdot 52 \\
460 \pm 102\end{array}$ & $\begin{array}{l}7 \cdot 2 \pm 2 \cdot 5 \\
0 \cdot 321 \pm 0.068 \\
1 \cdot 88 \pm 0.54 \\
1500 \pm 108\end{array}$ \\
\hline
\end{tabular}

Table Effect of single intravenous injection of tetragastrin on pancreatic secretion induced by Boots secretin in a dose $4 \cdot 0$ units $/ \mathrm{kg}-\mathrm{hr}^{1}$

${ }^{2}$ Values represent means $\pm S E$ for five experiments. Each dose of tetragastrin was given every three 15 -min period and the values during the first 15-min period after the administration are shown. The concentrations of zinc, calcium, and amylase, when increased in response to tetragastrin, fell below the pretreatment level during the second 15 -min period after the injection of all doses of tetragastrin. 


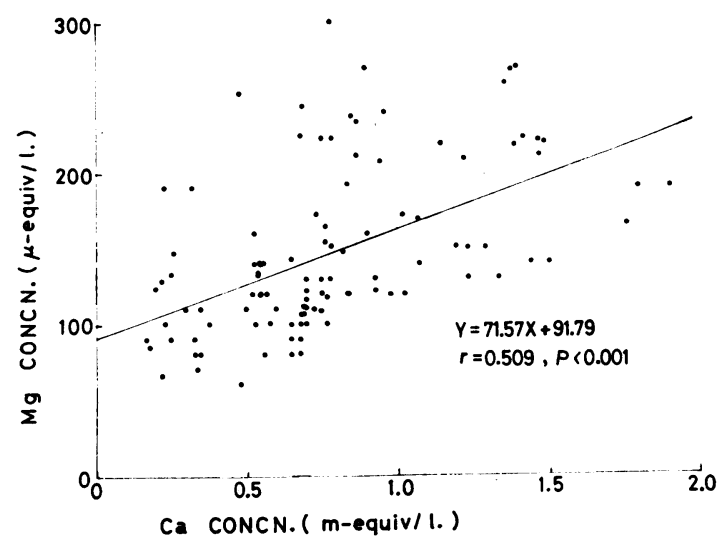

Fig 12 Relationship between magnesium and calcium concentration in 15-min samples of pancreatic juice secreted in response to continuous intravenous infusion of secretin alone and in combination with octa CCK-PZ, caerulein, or tetragastrin. Calculated regression line is shown.

chloride concentration compared with its voluminous flow (fig 14). The direct relationship between bicarbonate concentration and volume flow was limited to flow rates below $1.5 \mathrm{ml} /$ five min. Sodium and potassium concentrations remained constant throughout the experiment.

\section{Discussion}

The results presented here show that octa CCK-PZ, caerulein, and tetragastrin, when given intravenously,

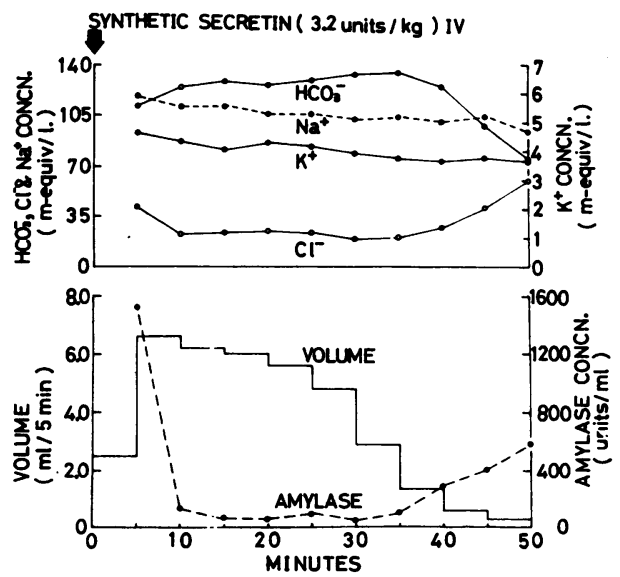

Fig 13 One experiment illustrating the effect of a single rapid intravenous injection of sccretin in a dose of $3 \cdot 2$ clinical units/kg on volume, electrolytes, and amylase concentrations in five-min samples of pancreatic juice. produce a highly significant increase in amylase, protein, calcium, and zinc concentrations of pancreatic juice secreted in response to submaximal doses of secretin. The volume of flow is to some extent augmented while bicarbonate, chloride, sodium, and potassium concentrations remain unaltered. Although the direct relation of bicarbonate concentration and the inverse relation of chloride to flow rate have generally been emphasized, it should be pointed out that this relationship is limited to low secretory rates below approximately $1.5 \mathrm{ml} /$ five min.

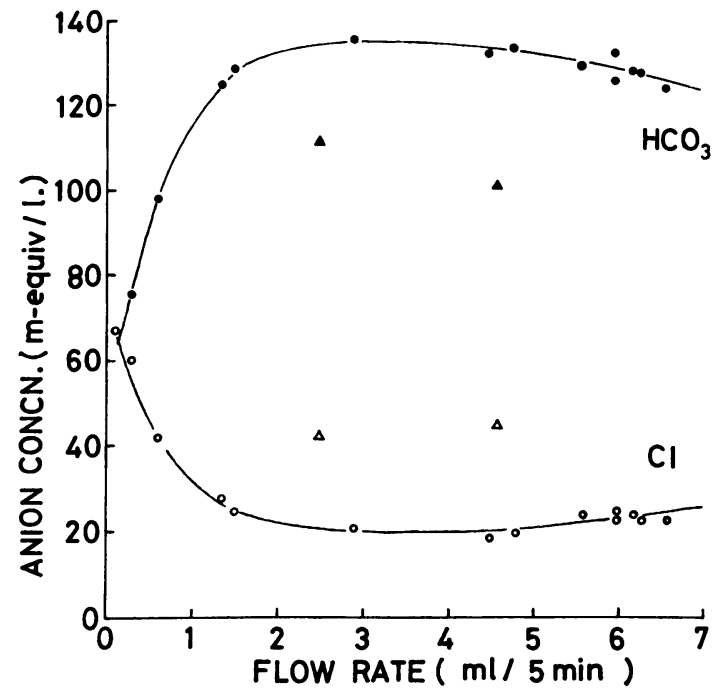

Fig 14 Relationship between volume flow and anion concentration in five-min samples of pancreatic juice secreted in response to a single rapid intravenous injection of synthetic secretin in a dose of 3.2 clinical units/kg. Closed symbols: $\mathrm{HCO}_{3} ;$ open symbols:C1. Triangles indicate the first five-min samples after secretin injection. Results of two experiments are plotted.

Thus, at higher flow rates with continuous secretin administration bicarbonate concentration increased to a peak and then declined progressively whereas volume flow increased throughout. This relation was unaffected by the addition of varying doses of octa CCK-PZ. A similar dissociation of bicarbonate and volume flow has previously been observed in unanaesthetized dogs by Christodoulopoulos, Jacobs, and Klotz (1961). In this regard, it is also interesting to note that at high secretory rates bicarbonate concentration tended to decrease with either continuous infusion or a single rapid injection of secretin.

Stening and Grossman (1969) have reported that gastrin, caerulein, and $10 \%$ pure CCK-PZ, each given alone, caused a dose-related increase above 
basal in volume and bicarbonate of canine pancreatic secretion in which mean flow was below $4.3 \mathrm{ml} / 15$ min. It has been reported recently that the maximal bicarbonate response to secretin was significantly augmented either by the intravenous infusion of CCK-PZ or the intraduodenal perfusion of phenylalanine (Meyer, Spingola, and Grossman, 1971). It seems most probable that the augmentation was due to an increase in volume flow rather than to an increase in bicarbonate concentration. While octa CCK-PZ and related peptides had no effects on bicarbonate concentration of secretin-stimulated pancreatic secretion at relatively high rates, the effects of these peptides on pancreatic secretion at low rates remain to be determined. In studying the pancreaticresponses to parasympathomimeticagents, Lenninger (1971) found that the intravenous injection of methacholine increased volume flow more when the pancreas was secreting at low rates than at high.

The pancreatic duct system behaves as a selective diffusion barrier between the lumen and the interstitium, but the mechanisms of this barrier function are not fully understood. Makhlouf and Blum (1970) have discussed the theoretical considerations which would permit all the three models for pancreatic secretion of bicarbonate and chloride to account equally well for the experimental observations. In the present study analysis of the anions in pancreatic juice obtained from the cannulated main duct shows that the slope $(-1 \cdot 14)$ of the regression line between bicarbonate and chloride concentrations was not significantly different from -1 and the sum of the two anions remained constant irrespective of the use of different secretory stimuli. Furthermore, the sum of the anions was usually greater than that of the cations. In contrast, Makhlouf and Blum have reported that the slope was significantly larger than -1 and the sum of the two anions increased as bicarbonate increased. The sum of the anions was significantly less than that of the cations at all levels. The reason for the discrepancies between the results in this study and those by Makhlouf and Blum is not known at present.

Sodium and potassium concentrations in pancreatic juice are approximately equal to those in the plasma, and both are independent of the rate of flow. The nature of the experiments reported in this paper does not permit distinction between the possible mechanisms responsible for the transport of sodium and potassium.

It has been demonstrated previously that intravenous injection of CCK-PZ produced a rapid increase in calcium and protein concentration in canine pancreatic juice secreted in response to secretin (Goebell, Steffen, Bode, and Hupe, 1970). The present data demonstrate that octa CCK-PZ, caerulein, and tetragastrin all caused a marked increase in amylase, protein, calcium, and zinc concentrations. In addition, significant linear correlations were observed between amylase and calcium, zinc and protein, and calcium and magnesium. It can be noted that similar correlations apply for each of the three peptides considered separately.

Alpha-amylases from various sources have been found to contain at least one gram-atom of calcium per mole of enzyme which plays a decisive role in preserving the integrity of the enzyme. Zinc is the only other metal found in stoichiometrically significant amounts (Vallee, Stein, Sumerwell, and Fischer, 1959). Pancreatic carboxypeptidase is also a zinc metalloenzyme containing one gram-atom of zinc per mole which is indispensable for its catalytic activity (Vallee and Neurath, 1955). The data presented therefore make it appear likely that at least part of these metals is associated with the corresponding metalloenzymes in pancreatic juice.

Magnesium is second in abundance to potassium as an intracellular cation. Some of the peptidases, including leucine aminopeptidase, which has been shown to be present in pancreatic juice (Christodoulopoulos et al, 1961), require magnesium as a cofactor (Wacker and Vallee, 1958). The finding that changes in magnesium concentration resembled but did not always parallel changes in calcium concentration suggests a different secretory origin of this ion.

Although a full elucidation of the role of divalent cations in pancreatic juice has to await further studies, there is a possibility that determination of the metals in pancreatic juice may constitute a satisfactory test for use in clinical examination of pancreatic function. Sullivan, O'Grady, and Lankford (1965) have shown that the content and concentration of zinc in duodenal aspirates before and after secretin stimulation in patients with chronic pancreatitis were lower than those in normal subjects. Since the present observations demonstrate significant changes in metal ion secretion in response to various polypeptide stimuli more attention might be paid to the secretion of these ions in pancreatic function tests.

The author is grateful to Dr M. A. Ondetti, Squibb Institute for Medical Research, New Brunswick, NJ, for the gift of octa CCK-PZ and secretin, Farmaceutici Italia, Milan, Italy, for caerulin, and Nissui Seiyaku Co, Tokyo, Japan, for tetragastrin. I would also like to acknowledge the encouragement and support of Drs S. Kikuchi, Y. Toda, and colleagues in the Pancreas Research Laboratory, 2nd Department of Medicine, Nagoya University School of Medicine. 


\section{References}

Anastasi, A., Erspamer, V., and Endean, R. (1968). Isolation and amino acid sequence of caerulein, the active decapeptide of the skin of Hyla caerulea. Arch. Biochem., 125, 57-68.

Caraway, W. T. (1959). A stable starch substrate for the determination of amylase in serum and other body fluids. Amer. J. clin. Path., 32, 97-99.

Christodoulopoulos, J. B., Jacobs, W. H., and Klotz, A. P. (1961). Action of secretin on pancreatic secretion. Amer. J. Physiol., 201, 1020-1024.

Cotlove, E. H., Trantham, H. V., and Bowman, R. L. (1958). An instrument and method for automatic, rapid, accurate, and sensitive titration of chloride in biologic samples. J. Lab. clin. Med., 51, 461-468.

Goebell, H., Steffen, C., Bode, C., and Hupe, K. (1970). Stimulierung der Calciumausscheidung im Pankreassaft von Hunden durch Pankreozymin. Klin. Wschr., 48, 755-757.

Lenninger, S. (1971). Effects of parasympathomimetic agents and vagal stimulation on the flow in the pancreatic duct of the cat. Acta physiol. scand., 82, 345-353.

Makhlouf, G. M., and Blum, A. L. (1970). An assessment of models for pancreatic secretion. Gastroenterology, 59, 896-908.

Meyer, J. H., Spingola, L. J., and Grossman, M. I. (1971). Endogenous cholecystokinin potentiates exogenous secretin on pancreas of dog. Amer. J. Physiol., 221, 742-747.

Mutt, V., and Jorpes, J. E. (1968). Structure of porcine cholecystokinin pancreozymin. 1. Cleavage with thrombin and with trypsin. Europ. J. Biochem., 6, 156-162.

Nakajima, S., Hirschowitz, B. I., Shoemaker, R. L., and Sachs, G. (1971). Inhibition of gastric acid secretion in vitro by C-terminal octapeptide of cholecystokinin. Amer. J. Physiol., 221, 10091013.

Nakajima, S., and Magee, D. F. (1970). Inhibition of exocrine pancreatic secretion oy glucagon and D-glucose given intravenously. Canad. J. Physiol., Pharmacol., 48, 299-305.
Natelson, S. (1951). Routine use of ultramicro methods in the clinical laboratory. Amer. J. clin. Path., 21, 1153-1172.

Plušcec, J., Sheehan, J. T., Sabo, E. F., Williams, N., Kocy, O., and Ondetti, M. A. (1970). Synthesis of analogs of the C-terminal octapeptide of cholecystokinin-pancreozymin: structureactivity relationship. J. Med. Chem., 13, 349-352.

Rubin, B. (1972). Some biological characteristics of cholecystokinin (CCK-PZ) and synthetic analogs.In Frontiers in Gastrointestinal Hormone Research (Nobel Symposium XVI), in press.

Rubin, B., Engel, S. L., Drungis, A. M., Dzelzkalns, M., Grigas, E. O., Waugh, N. H., and Yiacas, E. (1969). Cholecystokinin-like activities in guinea pigs and in dogs of the C-terminal octapeptide (SQ 19,844) of cholecystokinin. J. Pharm. Sci., 58, 955-959.

Segal, M. A. (1955). A rapid electrotitrimetric method for determining $\mathrm{CO}_{2}$ combining power in plasma or serum. Amer. J. clin. Path., 25, 1212-1216.

Slavin, W. (1968). Atomic Absorption Spectroscopy. Interscience Publishers, New York.

Snedecor, G. W., and Cochran, W. G. (1967). Statistical Methods, 6th ed. Iowa State University Press, Ames.

Stening, G. F., and Grossman, M. I. (1969). Gastrin-related peptides as stimulants of pancreatic and gastric secretion. Amer. J. Physiol., 217, 262-266.

Sullivan, J. F., O'Grady, J., and Lankford, H. G. (1965). The zinc content of pancreatic secretion. Gastroenterology, 48, 438-443.

Vallee, B. L., and Neurath, H. (1955). Carboxypeptidase, a zinc metallo-enzyme. J. biol. Chem., 217, 253-261.

Vallee, B. L., Stein, E. A., Sumerwell, W. N., and Fischer, E. H. (1959). Metal content of $\alpha$-amylases of various origins. J. biol. Chem., 234, 2901-2905.

Wacker, W. E. C., and Vallee, B. L. (1958). Magnesium metabolism. New Engl. J. Med., 259, 431-438. 